\title{
Litter size, infant mortality and female body weight in captive black-and-white ruffed lemurs Varecia variegata
}

\author{
Christoph Schwitzer ${ }^{1, *}$, Werner Kaumanns ${ }^{2}$ \\ ${ }^{1}$ Bristol Conservation and Science Foundation, Bristol Zoo Gardens, Clifton, Bristol BS8 3HA, UK \\ ${ }^{2}$ Eschenweg 5, 37130 Gleichen, Germany
}

\begin{abstract}
We describe the development of selected life history traits (infant mortality, litter size) in a captive primate population and assess the role of resource abundance in observed changes in these traits. We studied patterns in the long-term development of litter size and infant mortality in the world captive population of Varecia variegata comprising 2186 ind. registered in the International Studbook and in the European Regional Studbook over a period of $40 \mathrm{yr}$. We also collected body weight data from 98 ruffed lemurs in 14 European zoos. Infant mortality increased significantly over the study period and from the founder to the $\mathrm{F}_{1}$ generation, with a mean litter size of 1.78 in the wildborn founder generation, compared to 2.14 for the zoo-born generations combined. A litter size of 4 had the highest rate of survival per litter. Female body weight, which we found to increase over the generations, had a significant positive correlation with litter size, but did not correlate with infant mortality. We suggest that changes in life history traits of a captive primate population, such as those in infant mortality and litter size of $V$. variegata, may be due to altered living conditions in captivity and that these changes may ultimately lead to a loss of genetic variability. High female body weight in captivity may indirectly contribute to changes in the demographic structure of a population. Our results suggest that management tools to control such developments need to be established for use in coordinated breeding programmes for endangered species.
\end{abstract}

KEY WORDS: Population dynamics $\cdot$ Resource abundance $\cdot$ Primates $\cdot$ Small populations $\cdot$ Captive propagation $\cdot$ Selection processes $\cdot$ Life history traits $\cdot$ Obesity

\section{INTRODUCTION}

Captive populations of wild animals may exhibit the same low probability of long-term survival as the small population fragments that exist to an increasing extent in the wild (Ballou \& Foose 1996, Kaumanns et al. 2008). The long-term preservation of animal species in zoos as reserve and model populations with the potential for reintroduction into the wild is a primary goal of captive propagation (Foose 1991, WAZA 2005). Captive breeding programmes have been established to manage ex situ populations of endangered species with defined demographic and genetic structures over long periods of time. These programmes aim to min- imise the loss of genetic variability in the specific populations so that they may represent the gene pool of the founders as closely as possible, if the opportunity arises for individuals to be reintroduced into the wild (Foose 1991, Ballou \& Foose 1996). In both wild and captive populations, natural selection non-randomly influences allele frequencies (Hamrick \& Allard 1972, Frankham et al. 1986). In zoo populations, individuals possessing phenotypes that are best adapted to captive conditions will have the highest reproductive success (Frankham et al. 1986, Carlstead 1996), and selection processes will be most intense in the first few generations after the transition from wild to captive environments (Price 1984). 
Primates are kept in zoos in comparatively large numbers (Kaumanns et al. 2000b) and play an important role in captive propagation programmes. Of the 338 European captive wild animal populations coordinated in breeding programmes in December 2008, almost a quarter $(22.5 \%$; 76 species) were primates (EAZA 2008). Kaumanns et al. (2000a) evaluated the development of 30 managed primate populations in European zoos, and found evidence of large differences in reproductive success between females within a species. These findings imply that ongoing selection specific to the conditions of captivity may promote inequality in the size of breeding units and a decrease in effective population size.

Apart from predator pressure, one of the major selective forces acting on populations of wild primates is food availability (Wrangham 1987). In response to this pressure, primate species have evolved specific morphological, physiological and behavioural adaptations which allow them to effectively exploit the food resources in their habitats (Oates 1987). Altered foraging conditions in captivity in relation to quality of food, patterns of access to food, and amount of food consumed not only have behavioural consequences, but may also cause health problems such as obesity, which is indeed commonly seen in captive primates (e.g. Cousins 1972, Walike et al. 1977, Savage et al. 1993, Schwartz et al. 1993, Encarnación \& Heymann 1998, Araújo et al. 2000, Chen et al. 2002, Schmidt 2004, Videan et al. 2007), particularly in Malagasy lemurs (Schaaf \& Stuart 1983, Pereira \& Pond 1995, Schwitzer \& Kaumanns 2001a, Polowinsky \& Schwitzer 2009, Willis et al. 2009). Terranova \& Coffman (1997) conducted a quantitative study on a large sample of lemurs and found significant differences in weights between wild and captive individuals, with 9 species and subspecies showing obesity rates of between 17 and $95 \%$ in captivity.

The abundance of food resources may directly influence the reproductive output of a population (Pereira 1993, Richard et al. 2000, Ratsimbazafy et al. 2002, Louis et al. 2005, Vasey \& Borgerson 2009). For instance, Pereira (1993) found that semi-captive ring-tailed lemurs Lemur catta increased the proportion of multiple births from just above 0 under low food provisioning $(1.0 \mathrm{~kg}$ Chow per 40 ind.) to $>40 \%$ under high food provisioning (7.6 kg Chow and fruit per 40 ind.). A group of wild $L$. catta at the Berenty Reserve, Madagascar, which the author (Pereira 1993) used for comparison, had 2 to $3 \%$ incidence of multiple births. Wild Varecia variegata in the Manombo Forest, Madagascar did not reproduce at all for at least $3 \mathrm{yr}$ after a cyclone had destroyed $~ 50 \%$ of the woody vegetation in the forest (Ratsimbazafy et al. 2002). Similar observations were made on V. rubra in the Masoala National Park, also Madagascar, by Vasey \& Borgerson (2009). These results are not only compatible with the assumption that food is a selection factor, but also indicate that on a proximate level, it has the potential to modify the demography of a primate population within a short time span.

Lemurs, with their high reproductive output and short generation times, provide a good opportunity to study the effects of resource abundance on population dynamics. Such processes are challenging to study in the wild since one would need to collect data from several generations (Prout 1969, Dunbar 1985); however, captive populations can be used as models since demographic and other relevant data are available over several generations and long periods of time for some species. Results of such studies can be of value to in situ conservation, allowing predictions to be made regarding small and fragmented, managed populations. The captive propagation programme for the ruffed lemur Varecia variegata, which is used as the model species in the present study, is probably the largest of any primate species. The European Regional Studbook alone counted 731 living individuals of 3 subspecies at the end of 2002 (Schwitzer \& Kaumanns 2004).

Here, we investigate infant mortality and litter size in the captive population of black-and-white ruffed lemurs over 4 decades and 5 generations. We analyse the development of these life history traits in reference to female body weight. Body weight is regarded as a factor that may trigger changes in individual reproductive output over time, thus possibly inducing changes in some life history parameters in the long run. With the present study, we aim to provide materials for the critical evaluation and improvement of the way in which ex situ conservation programmes for primates are currently being run.

\section{MATERIALS AND METHODS}

Data from the International Studbook (Porton 1997) as well as from the European Regional Studbook for the ruffed lemur (Schwitzer \& Kaumanns 2001b), referring to 2186 Varecia variegata (1054 males, 854 females, and 278 ind. of unknown sex), were entered into the software package SPARKS 1.42 (Scobie 1997) and analysed for infant mortality and litter size. This yielded a sample of 987 litters from 268 females, comprising a total of 2061 infants. Demographic analyses were conducted using DEMOG 4.2 (Bingaman-Lackey \& Ballou 1997). For the analyses of litter size and infant mortality across generations, the generation to which an individual belonged was determined using its descent in the female line (e.g. an offspring from a mother belonging to the 3rd generation was assigned to the 4 th generation, regardless of which generation the father belonged to). Infant mortality was defined as an infant dying before it was fully weaned, i.e. within the first 5 mo of its life (Hick 1984). 
The female ruffed lemurs in this sample were normally kept in breeding pairs or small family units (i.e. pairs with their offspring). Keeping conditions for ruffed lemurs in European zoos did not change over time.

Body weights of 25 Varecia variegata and $18 \mathrm{~V}$. rubra were taken at the zoos in Cologne, Mulhouse and Münster using a Sartorius ISI 20 scale (Sartorius AG) to a precision of $10 \mathrm{~g}$. Additionally, body weight data for $40 \mathrm{~V}$. variegata and $15 \mathrm{~V}$. rubra were received from 14 European zoos via a questionnaire sent to 110 institutions participating in the European Endangered Species Programme (EEP) for ruffed lemurs. The latter weights were taken over a period of 10 yr. A 1-way ANOVA and subsequent $F$-test did not reveal significant differences in body weight, litter size or infant mortality between the $V$. variegata and $V$. rubra in our sample; thus analyses of the effects of female body weight on litter size and infant mortality were carried out using the data from both Varecia species to increase sample size. A more detailed analysis of the $V$. rubra population will be presented elsewhere.

Only the weights of adult females ( $>2$ yr of age; Hick 1984) of known age that had produced offspring by the time of weighing were used for analyses. Where an animal was weighed more than once, the mean value was taken. Females known to have been pregnant at the time of weighing were excluded from analyses. The possibility of pregnancy of some females in the dataset acquired through the questionnaire could not be excluded (available data did not provide reliable information on pregnancies); however, neither Schaaf \& Stuart (1983) nor Terranova \& Coffman (1997) found differences in captive lemur body weights among seasons, which suggests that differences in weight between pregnant and non-pregnant females of these seasonally breeding species may not be significant.

For all statistical analyses, the software package SPSS 7.5 (Statsoft) was used. Non-parametric MannWhitney $U$-tests were performed to test for differences in: infant mortality and litter size between generations, infant mortality between different litter sizes, and litter size between females of different body weight categories. Linear regression analyses were carried out to show changes in infant mortality over the years and changes in female body weight over the generations. Pearson correlations were used to test the relationships between female body weight and infant mortality as well as litter size. The level of significance was set to $\mathrm{p}<0.05$. When $0.05<\mathrm{p}<0.1$, a trend was reported.

\section{RESULTS}

\section{Demographic analysis}

Litter size

Mean litter size of the black-and-white ruffed lemur population from 1969 until 2000 was $2.09 \pm 0.25$ (SD) (n = 987 litters from 268 females). Litters consisting of only one offspring comprised $29.9 \%$, twins $38.6 \%$, triplets $25.4 \%$, quadruplets $5.0 \%$, and quintuplets $1.1 \%$ of the total. The proportion of larger litters ( $>2$ infants) increased over the generations, whereas the proportion of singletons and twins decreased (Fig. 1).

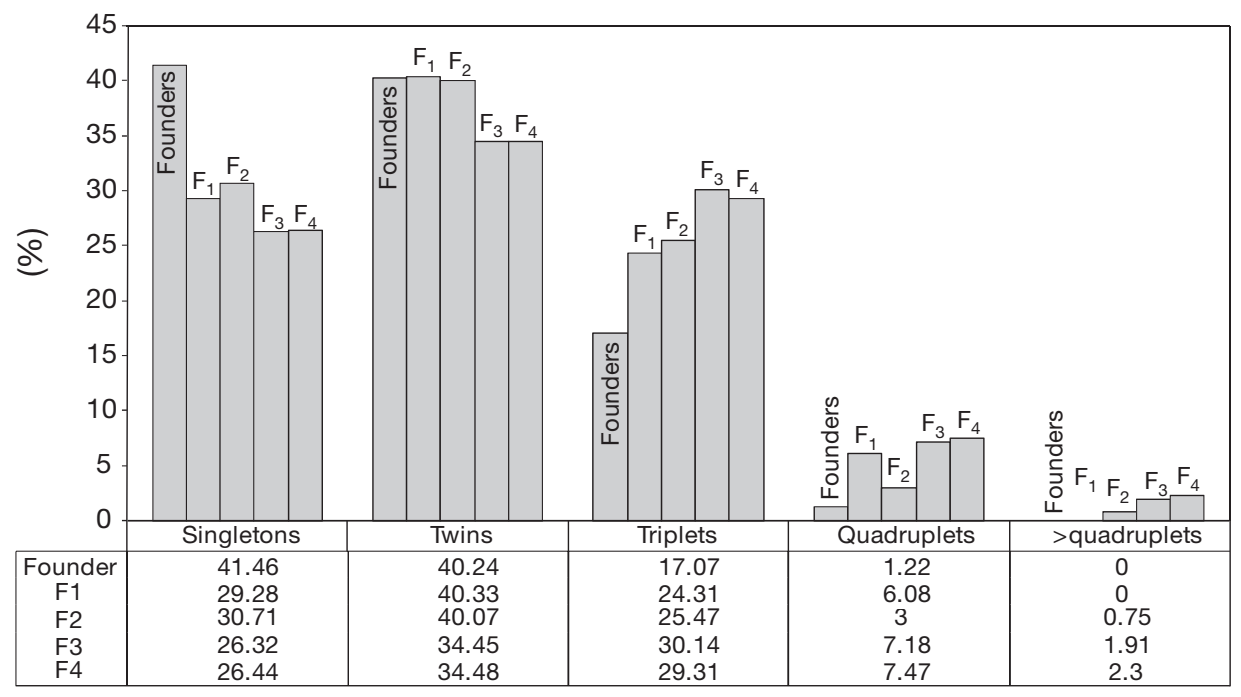

Litter size

Fig. 1. Varecia variegata. Proportions of litters with sizes of $1,2,3,4$, and $>4$, in different generations (Founder to $F_{4}$ ) of the world captive population ( $\mathrm{n}=913$ litters, comprising a total of 1922 infants; see 'Results: Demographic analysis' for statistics) 
Differences between the generations were however insignificant (Mann-Whitney $U$-test: $\mathrm{p}>0.05 ; 2$-tailed). Whereas the wild-born founder generation had an average litter size of 1.78 , the average litter size for zoo-born generations $\mathrm{F}_{1}$ to $\mathrm{F}_{4}$ was 2.14 .

\section{Infant mortality}

Mean annual infant mortality in the Varecia variegata world captive population was $32.3 \%$ (range: 0 to $66.7 \%$ ), while total infant mortality was $36.6 \%$. Infant mortality showed a significant increase over the years (linear regression: $B=0.7$; $<<0.01$; Fig. 2).

Table 1 shows the mean proportion of infant mortality and the mean number of surviving offspring per litter for a given litter size. The number of survivors per litter increased from a litter size of 1 to a litter size of 4 and then decreased again. The differences in the number of survivors per litter between 2 successive litter sizes were significant (Mann-Whitney $U$-test: litter size $1-2$ : $U=29230, \mathrm{p}<0.01 ; 2-3: U=29297.5, \mathrm{p}<$ $0.01 ; 3-4: U=4119, \mathrm{p}<0.01 ; 2$-tailed), but not the difference between a litter size of 4 and a litter size $>4$ (Mann-Whitney $U$-test: $\mathrm{p}>0.05$; 2-tailed).

The numbers and proportions of surviving infants, infant mortality, and the proportions of males born over the generations are shown in Table 2. Infant mortality increased from the founder to the $\mathrm{F}_{3}$ generation and then stagnated, whereas the proportion of males born (irrespective of their survival) slightly decreased
Table 1. Varecia variegata. Captive world population: number of infants, infant mortality, and number of surviving infants per litter for litter sizes of 1 to $>4$ (mean $\pm \mathrm{SD}_{i} \mathrm{n}=987$ litters comprising a total of 2061 infants; see 'Results: Infant mortality' for statistics). DNS = did not survive

\begin{tabular}{|lcccc|}
\hline $\begin{array}{l}\text { Litter } \\
\text { size }\end{array}$ & Infants & DNS & DNS (\%) & Survivors litter \\
\hline 1 & 295 & 119 & $40.3 \pm 49.0$ & $0.60 \pm 0.49$ \\
2 & 762 & 270 & $35.4 \pm 42.0$ & $1.29 \pm 0.84$ \\
3 & 753 & 262 & $34.8 \pm 38.1$ & $1.96 \pm 1.14$ \\
4 & 196 & 68 & $34.7 \pm 36.4$ & $2.61 \pm 1.45$ \\
$>4$ & 55 & 36 & $65.5 \pm 34.2$ & $1.73 \pm 1.71$ \\
\hline
\end{tabular}

from the founder to the $\mathrm{F}_{4}$ generation (although not significantly; Mann-Whitney $U$-test: $\mathrm{p}>0.05$; 2-tailed). The difference in the proportion of surviving infants (i.e. in infant mortality) between the founder and the $\mathrm{F}_{1}$ generation was significant (Mann-Whitney $U=150$; $0.01<\mathrm{p}<0.05 ;$ 2-tailed), but differences between the other generations were not.

\section{Effects of female body weight}

The mean body weight of 98 captive ruffed lemurs from 14 European zoos was $3933 \pm 852 \mathrm{~g}$, ranging from 2940 to $8000 \mathrm{~g}$. There was no significant difference in body weights between males and females (males: $3938 \pm 776$ g, females: $3926 \pm 933$ g; 1-way ANOVA: $\mathrm{p}>0.05 ; F=0.0)$.

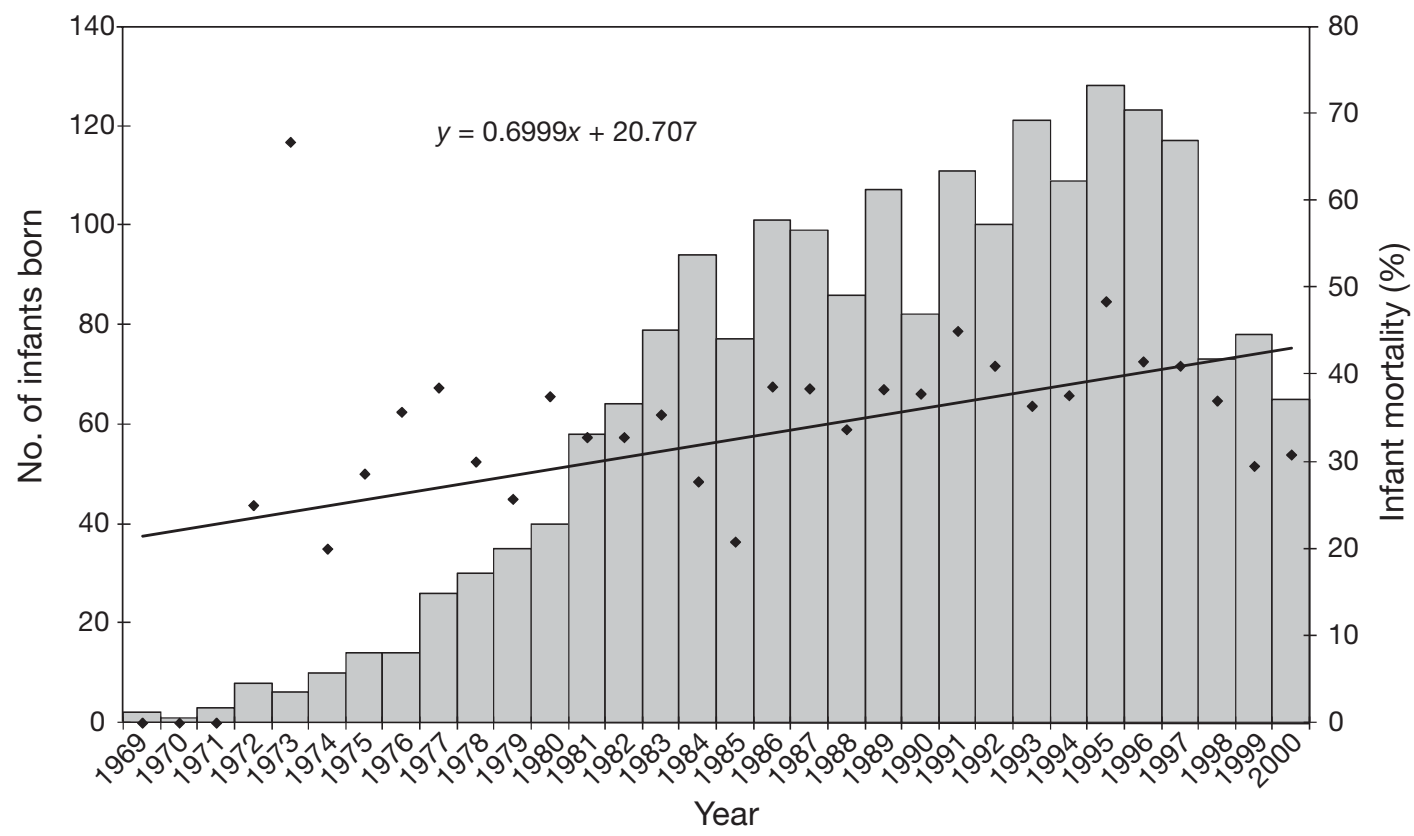

Fig. 2. Varecia variegata. Number of births (bars) and relative infant mortality $(\diamond)$ of the world captive population from 1969-2000 ( $\mathrm{n}=987$ litters, comprising a total of 2061 infants; linear regression: $B=0.7 ; \mathrm{p}<0.01$ ) 
Although there was a trend of increasing body weights of female ruffed lemurs with increasing generation, this trend was not significant (linear regression: $B=153.0 ; \mathrm{p}>$ 0.05; Fig. 3).

Female body weight and litter size

Mean litter sizes were plotted against the body weights of females (Fig. 4). The positive correlation between mean litter size and female body weight was significant (Pearson correlation: $\mathrm{r}=0.3 ; 0.01<\mathrm{p}<0.05$; 1 -tailed).

Fig. 5 shows the difference in mean litter size for 2 categories of females: those weighing below $4000 \mathrm{~g}$ (the upper limit of the body weight range of wild female Varecia given by Vasey 2003), and those weighing $\geq 4000 \mathrm{~g}$. Heavier females had significantly larger litter sizes than leaner ones $(2.58 \pm 0.74>2.09 \pm$ 0.42; Mann-Whitney $U=46$; $p<0.05$; 2-tailed).

Female body weight and infant mortality

The relationship between female body weight and infant mortality is shown in Fig. 6. The correlation between the variables was not significant (Pearson correlation: $r=0.3 ; 0.07>p>0.05 ; 1$-tailed).

\section{DISCUSSION}

In the present study, we investigated changes in infant mortality and litter size over time and generations in the world captive population of black-andwhite ruffed lemurs. Hypothesising that food resource abundance is a factor that may trigger changes in reproductive output (Pereira 1993, Richard et al. 2000, Ratsimbazafy et al. 2002, Louis et al. 2005, Vasey \& Borgerson 2009), we looked at possible relationships between female body weight (as an indirect measure of food abundance) and litter size as well as between body weight and infant mortality (as measures of reproductive output; Weigler et al. 1994).

A few studies that analysed ruffed lemur reproductive output with regard to litter size, either in a single institution (Shideler \& Lindburg 1982, Hick 1984, Rasmussen 1985, Brockman et al. 1987, Weigler et al. 1994), or in the world captive population from the corresponding studbook records (Noble et al. 1990) were published in the 1980s and 1990s. The results of these studies are predominantly compatible with ours, but some deviate slightly from our findings as discussed in the following. Since the dataset used in this study

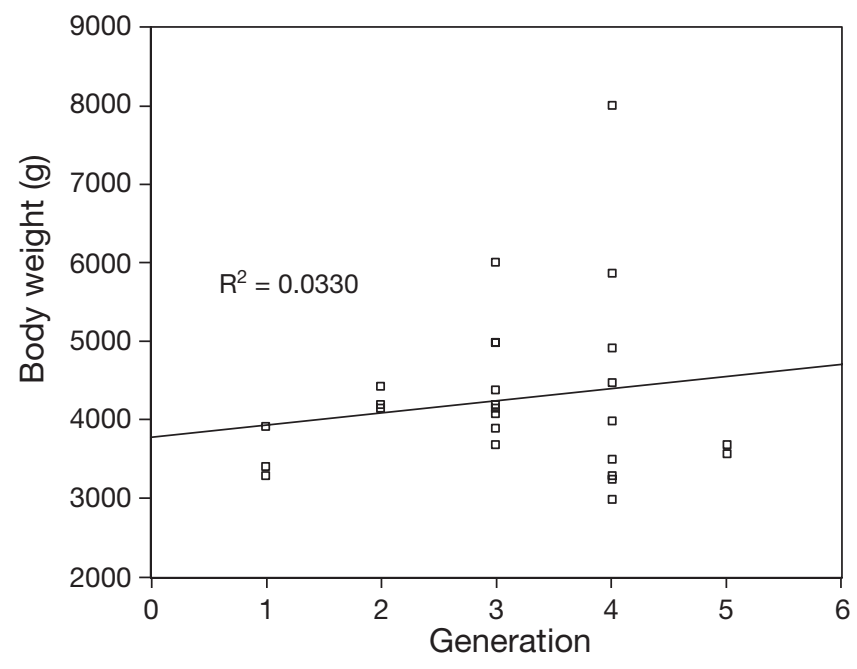

Fig. 3. Varecia variegata. Body weights of females from different generations $(\mathrm{n}=27$; linear regression: $B=153.0 ; \mathrm{p}>0.05$ )

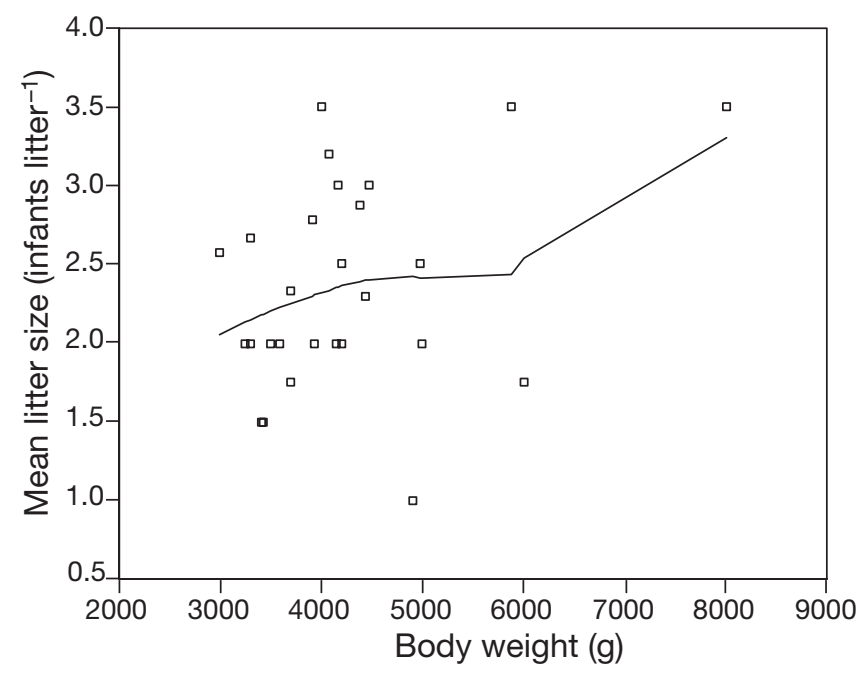

Fig. 4. Varecia variegata. Relationship of mean litter size and body weight in captive females. The curve shows the Lowess fit to the entire data scatter $(\mathrm{n}=27$; Pearson correlation: $\mathrm{r}=0.3 ; 0.01<\mathrm{p}<0.05 ; 1$-tailed) 
includes all those of the previous works, and provided that historical studbook data have been recorded correctly, we assume that differences in results concerning the total captive population may be due to the smaller sample sizes of the earlier investigations.

Litters of zoo-born ruffed lemurs comprised on average 2.14 infants, whereas litters of wild-born captive individuals had a mean size of only 1.78. Reliable estimates of mean litter size of wild female ruffed lemurs are difficult to obtain since infants that die soon after

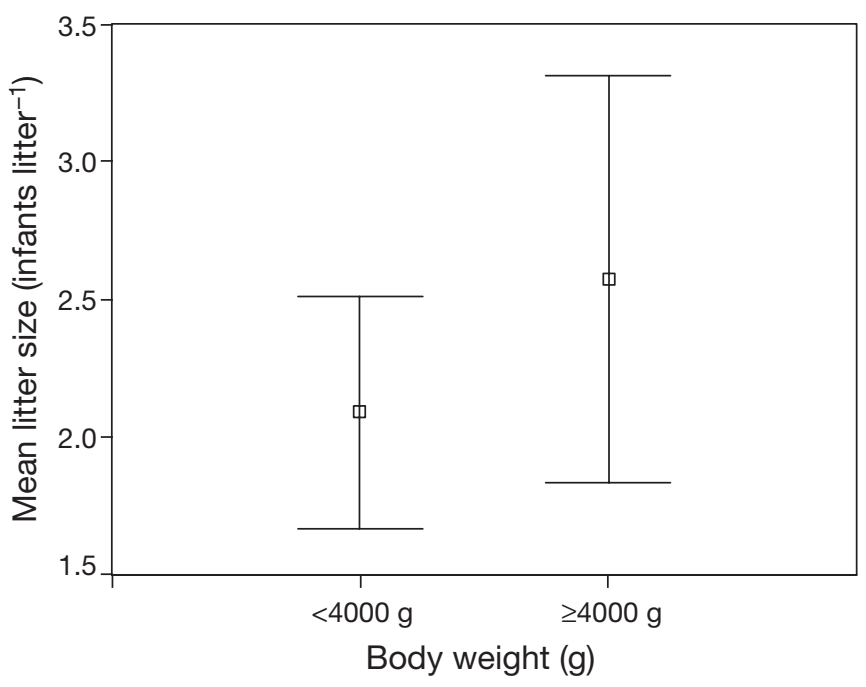

Fig. 5. Varecia variegata. Litter sizes of captive females weighing $<4000(\mathrm{n}=12)$ and $\geq 4000 \mathrm{~g}(\mathrm{n}=15)$, respectively (mean $\pm \mathrm{SD} ; \mathrm{n}=27$; Mann-Whitney $U=46 ; \mathrm{p}<0.05 ;$ 2-tailed)

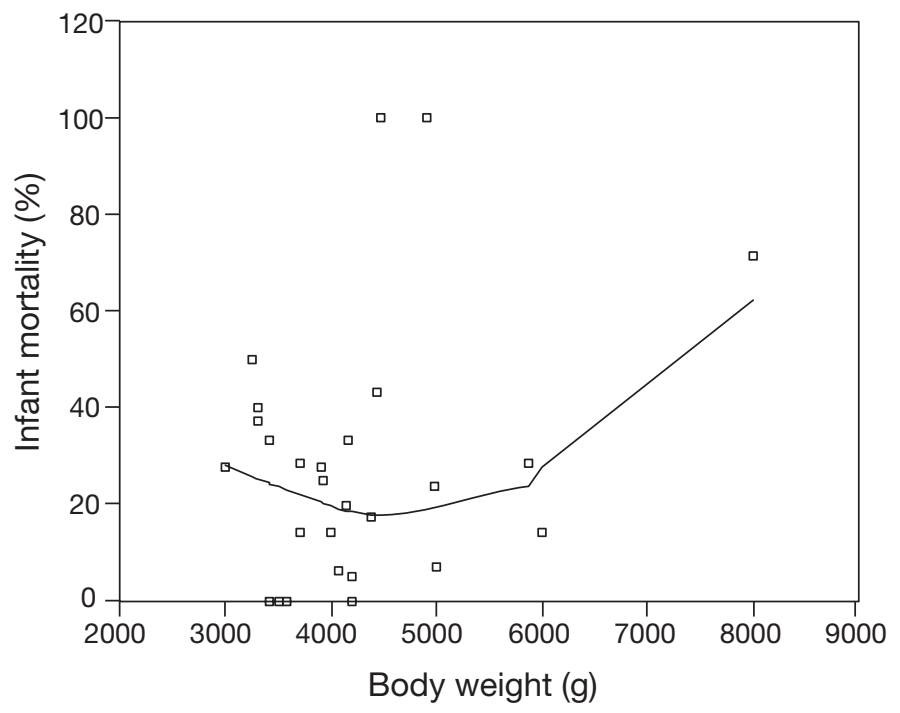

Fig. 6. Varecia variegata. Relationship between captive female body weight and infant mortality. The curve shows the Lowess fit to the entire data scatter $(\mathrm{n}=27$; Pearson correlation: $r=0.3 ; 0.07>p>0.05 ; 1$-tailed) birth may not always be found by the observer (see Morland 1990). Unlike in captive ruffed lemurs, rearing of offspring in 2 consecutive years by wild females appears to be uncommon (Morland 1990, Merenlender et al. 1998, Rakotondratsima \& Kremen 2001, Vasey 2007). Although the annual mean female reproductive output (surviving offspring) was as low as 0.58 in Morland's (1990) study and even lower in the study of Merenlender et al. (1998), in most cases the animals probably gave birth to twins (Morland 1990). This still seems to be reflected in the pattern of litter sizes in the captive population (see also Brockman et al. 1987), but the proportion of litters $>2$ has increased over the generations. However, contrary to the findings of Noble et al. (1990), these increases were not determined to be either continuous or significant.

In our study, contrary to the findings of Shideler \& Lindburg (1982) at San Diego Zoo, survivorship was associated with litter size in that significantly more infants per litter survived in litters of 4 than in litters of any other size. This result, together with the aforementioned trend towards larger litters, suggests that the conditions in captivity for Varecia variegata probably support a higher litter size than those in the wild habitat, and that the proportion of females producing larger litters increases in the first zoo-born generation. This supports the assumption that proximate factors such as the quality of food and the absence of predation have already influenced female reproductive output at an early period of the population's history. This is in accordance with Price's (1984) suggestion that selection processes will be most intense in the first few generations after the transition from wild to captive environments.

Surprisingly, infant mortality was lowest in litters of 4. Combined with the fact that mean litter size showed an increase over the generations, one would also expect infant mortality to show a general decline. In contrast, our results show an increase in infant mortality over the course of the study period. This is surprising, especially when we consider the fact that the keeping conditions in zoos (hygiene, veterinary care) have greatly improved since the early 1960s. The trend of continuing high infant mortality also seems to apply to other captive primate populations (Kaumanns et al. 2008). Analyses of data on apes as well as on Saguinus oedipus and Macaca silenus show the same general direction (Kaumanns et al. 2000a, 2004, Köhnen 2002).

In Varecia variegata, infant mortality increased significantly from the founder to the $F_{1}$ generation, suggesting that a considerable proportion of the individuals' capability to successfully produce and rear offspring may have been lost with the transition from the wild-born to the first zoo-born generation of lemurs. This loss of individual capability may have 
been due to the probable lack of opportunity for zooborn ruffed lemurs to grow up in a totally speciestypical social and physical environment (Schwitzer \& Kaumanns 2001b). In addition, the conditions in captivity may have had adverse effects on the immune system of the animals, as a preliminary analysis of lemur infant deaths from one institution revealed that $64.7 \%$ of all deaths with known causes (11 out of 17) were due to infectious diseases (Schwitzer et al. unpubl. data; but see Brockman et al. 1988).

With reference to ex situ management programmes for endangered species, the findings of this study, which partly contradict previous expectations, strongly suggest that assessment of the breeding performance of a population should include the analysis of as many relevant variables as possible, in order to determine the contribution of the various 'subunits' of the reproductive system to possible breeding problems.

According to Hume (1995), nutrition is a predominant factor controlling reproductive rate and resistance to diseases in natural animal populations. Although other factors may play a role, animal population density is likely to be ultimately controlled by food resources (Lack 1954, cf. Hume 1995). In species producing litters, litter size is likely to be a regulatory mechanism to ensure maximum reproductive output under variable environmental conditions in the wild habitat (e.g. resource availability during the birth and weaning seasons) (Jaquish et al. 1996, Balko \& Underwood 2005). If a high level of nutrition increased reproductive output, the body weight of females should show a positive correlation with the mean litter size of these females. Moreover, if the survivability of offspring increased with higher food abundance, infant mortality and female body weight should show a negative correlation. We did not use total reproductive output per female for correlation with body weight, as a reliable quantification was not possible with the dataset in hand (e.g. it was not possible to tell if a female that did not have offspring in a certain year had had the opportunity to mate in the preceding breeding season).

The results showed that for both Varecia species combined (data from both species were used so as to increase the sample size for female body weight), female body weight was significantly positively correlated with litter size. There was, however, no correlation between female body weight and infant mortality, although a trend of increasing female body weight over the generations was apparent. These findings are compatible with those of a number of studies on other species, which also found relationships between reproductive output and nutrition (e.g. Rhine et al. 1988, Pereira 1993, Jaquish et al. 1996, Adler \& Beatty 1997, cf. Wright 1999, Richard et al. 2000, Ratsimbazafy et al.
2002, Vasey \& Borgerson 2009). For instance, Jaquish et al. (1996), who studied genetic and environmental influences on litter size in 3 species of callitrichids, suggested that litter size is influenced more by environmental conditions than by heredity, speculating that larger litters are primarily a reaction to abundant food resources. Köhnen (2002), in her study of population development in a captive colony of cotton-top tamarins Saguinus oedipus, also speculated that the increase in litter size in the study population over the years was related to a high level of nutrition. Like some lemur species, callitrichids can produce litters of $>1$ offspring. Primate species with the potential to produce litters may regulate reproductive output in adaptation to environmental conditions by adjusting litter size, rather than by adjusting inter-birth intervals or size of the infant, as species with single births may do.

In lemurs, the influence of nutrition on reproduction has rarely been researched in detail. Pereira (1993), in his study on the seasonality of growth rate and adult body weight in semi-captive Lemur catta, found that the proportion of twin births increased by $>40 \%$ under a regime of high food provisioning. Other studies found that in some years, wild lemur groups had more surviving infants than in other years or did not reproduce at all (e.g. Morland 1991a,b, Sauther 1998, Richard et al. 2000, Ratsimbazafy et al. 2002, Louis et al. 2005, Vasey \& Borgerson 2009), although both actual food intake and reproductive output are difficult to measure accurately in the wild. In addition, Schaaf \& Stuart (1983) suggest a negative effect of obesity on reproductive performance in captive Eulemur mongoz, but do not support this claim with data.

In the present study, we investigated the complex interrelations between body condition, expressed as female body weight, and population dynamics parameters such as litter size and infant mortality in captive lemurs. For the first time, we related data on the development of a very large captive primate population to body weight data. Our results show that body condition, and thus nutrition, is an important factor in the management of small populations under altered conditions; it also has the potential to promote changes in population dynamics and, in the medium term, to enhance the loss of genetic variability by increasing the reproductive output of certain genetic lines, thus promoting inequality in family sizes. Diets for animals in captivity thus need to be closely monitored with regard to their nutrient and, specifically, their energy content. If zoo populations are kept as reserve populations that may some day need to be reintroduced into the wild, these populations should be managed in a way that preserves as much of the original genotypic and phenotypic variability as possible (Kaumanns 1994). 
Further studies should focus on the proximate mechanisms of food intake regulation in lemurs, as well as on the physiological mechanisms that relate e.g. female body weight to litter size. More body weight data as well as data on food intake, both from wild and captive lemurs, need to be collected systematically to increase sample size for future studies.

\section{CONCLUSIONS}

Captive populations of primates, although managed in coordinated breeding programmes, may show unwanted changes in population dynamics after only a few generations. This can ultimately result in loss of genetic variability.

Changes, such as those shown here with regard to infant mortality and litter size, may be due to conditions in captivity not resembling those in the respective species' wild habitats, thus promoting alterations in the adaptive phenotype after a short time span. One such condition may be high resource abundance.

Zoo populations should be continuously analysed for eventual changes in their dynamics over time or generations, and management tools to cope with such developments need to be established.

Acknowledgements. We thank everybody who provided data for this study, especially the institutions participating in the European Endangered Species Programme (EEP) for Varecia variegata. We also thank N. Maier, S. Sinderdinck, S. Polowinsky and N. Koene for help in assembling the historical data of the studbook population; C. Solman and F. Ruperti for correcting our clumsy English; and J. Ratsimbazafy and two anonymous reviewers for commenting on an earlier version of this manuscript. C.S. was supported by a PhD scholarship from the Konrad-Adenauer-Stiftung e.V.

\section{LITERATURE CITED}

Adler GH, Beatty RP (1997) Changing reproductive rates in a neotropical forest rodent, Proechimys semispinosus. J Anim Ecol 66:472-480

Araújo A, Arruda MF, Alencar AI, Albuquerque F, Nascimento MC, Yamamoto ME (2000) Body weight of wild and captive common marmosets (Callithrix jacchus). Int J Primatol 21:317-324

Balko EA, Underwood HB (2005) Effects of forest structure and composition on food availability for Varecia variegata at Ranomafana National Park, Madagascar. Am J Primatol 66:45-70

Ballou JD, Foose TJ (1996) Demographic and genetic management of captive populations. In: Kleiman DG, Allen ME, Thompson KV, Lumpkin S (eds) Wild mammals in captivity - principles and techniques. University of Chicago Press, Chicago, IL, p 263-283

Bingaman-Lackey L, Ballou JD (1997) DEMOG 4.2: demographic analysis software. National Zoo, Washington, DC

Brockman DK, Willis MS, Karesh WB (1987) Management and husbandry of ruffed lemurs, Varecia variegata, at the
San Diego Zoo (II): reproduction, pregnancy, parturition, litter size, infant care and reintroduction of hand-raised infants. Zoo Biol 6:349-363

Brockman DK, Willis MS, Karesh WB (1988) Management and husbandry of ruffed lemurs, Varecia variegata, at the San Diego Zoo (III): medical considerations and population management. Zoo Biol 7:253-262

Carlstead K (1996) Effects of captivity on the behavior of wild mammals. In: Kleiman DG, Allen ME, Thompson KV, Lumpkin S (eds) Wild mammals in captivity - principles and techniques. University of Chicago Press, Chicago, IL, p 317-333

> Chen Y, Ono F, Yoshida T, Yoshikawa Y (2002) Relationship between body weight and hematological and serum biochemical parameters in female cynomolgus monkeys (Macaca fascicularis). Exp Anim Tokyo 51:125-131

Cousins D (1972) Diseases and injuries in wild and captive gorillas: Gorilla gorilla. Int Zoo Yearb 12:211-218

Dunbar RIM (1985) Population consequences of social structure. In: Sibly RM, Smith RH (eds) Behavioural ecology. Ecological consequences of adaptive behaviour. Blackwell Scientific Publications, Oxford

- Encarnación F, Heymann EW (1998) Body mass of wild Callimico goeldii. Folia Primatol 69:368-371

EAZA (European Association of Zoos and Aquaria) (2008) Breeding programmes. www.eaza.net/, accessed 27 Nov 2008

Foose TJ (1991) Viable population strategies for re-introduction programmes. In: Gipps JHW (ed) Beyond captive breeding - re-introducing endangered mammals to the wild. Zool Soc Lond Symp 62:165-172

Frankham R, Hemmer H, Ryder OA, Cothran EG, Soulé ME, Murray ND, Snyder M (1986) Selection in captive populations. Zoo Biol 5:127-138

Hamrick JL, Allard RW (1972) Microgeographical variation in allozyme frequencies in Avena barbata. Proc Natl Acad Sci USA 69:2100-2104

Hick U (1984) Haltung, Zucht und künstliche Aufzucht von Varis. Z Kölner Zool 27:123-137

Hume ID (1995) General concepts of nutrition and nutritional ecology. In: Ganslosser U, Hodges JK, Kaumanns W (eds) Research and captive propagation. Filander Verlag, Fürth, p 90-98

Jaquish CE, Cheverud JM, Tardif SD (1996) Genetic and environmental impacts on litter size and early infant survival in three species of callitrichids. J Hered 87:74-77

Kaumanns W (1994) The 'quality' of captive primate populations. Primate Rep 39:127-132

Kaumanns W, Schwitzer C, Klumpe K, Schmid P (2000a) How are primate breeding programmes doing? An overview and preliminary analysis. In: Rietkerk F, Hiddinga B, Brouwer K, Smits S (eds) EEP Yearbook 1998/99. EAZA Executive Office, Amsterdam, p 448-460

Kaumanns W, Hampe K, Schwitzer C, Stahl D (2000b) Primate nutrition - towards an integrated approach. In: Nijboer J, Hatt JM, Kaumanns W, Beijnen A, Gansloßer U (eds) Zoo animal nutrition. Filander Verlag, Fürth, p 91-106

Kaumanns W, Krebs E, Nogge G (2004) Menschenaffen in Menschenhand. Langzeitentwicklung europäischer Menschenaffenpopulationen. Zool Garten NF 74:217-228

Kaumanns W, Singh M, Krebs E, Schwitzer C (2008) Primate populations in zoos: A case of fragmentation. Primate Rep $76: 41-54$

Köhnen N (2002) Die Entwicklung einer Lisztaffenkolonie (Saguinus oedipus oedipus) und Ausschlüsse von Gruppenmitgliedern. University of Cologne

Lack D (1954) The natural regulation of animal numbers. Oxford University Press, Oxford 
Louis EE Jr, Ratsimbazafy JH, Razakamaharauo VR, Pierson DJ, Barber RC, Brenneman RA (2005) Conservation genetics of black and white ruffed lemurs, Varecia variegata, from southeastern Madagascar. Anim Conserv 8:105-111

Merenlender A, Kremen C, Rakotondratsima M, Weiss A (1998) Monitoring impacts of natural resource extraction on lemurs of the Masoala Peninsula, Madagascar. Conserv Ecol 2:5, available at www.consecol.org/vol2/iss2/art5/

Morland HS (1990) Parental behaviour and infant development in ruffed lemurs in a northeast Madagascar rain forest. Am J Primatol 20:253-265

Morland HS (1991a) Preliminary report on the social organization of ruffed lemurs (Varecia variegata variegata) in a northeast Madagascar rain forest. Folia Primatol (Basel) 56:157-161

Morland HS (1991b) Social organization and ecology of black and white ruffed lemurs (Varecia variegata variegata) in lowland rain forest, Nosy Mangabe, Madagascar. PhD dissertation, Yale University, New Haven, CN

> Noble SJ, Chesser RK, Ryder OA (1990) Inbreeding effects in captive populations of ruffed lemurs. Hum Evol 5:283-291

Oates JF (1987) Food distribution and foraging behaviour. In: Smuts BB, Cheney DL, Seyfarth RM, Wrangham RW, Struhsaker TT (eds) Primate societies. University of Chicago Press, Chicago, IL, p 197-209

Pereira ME (1993) Seasonal adjustment of growth rate and adult body weight in ring-tailed lemurs. In: Kappeler PM, Ganzhorn JU (eds) Lemur social systems and their ecological basis. Plenum Press, New York, p 205-221

Pereira ME, Pond CM (1995) Organization of white adipose tissue in Lemuridae. Am J Primatol 35:1-13

Polowinsky SY, Schwitzer C (2009) Nutritional ecology of the blue-eyed black lemur (Eulemur flavifrons): integrating in situ and ex situ research to assist the conservation of a critically endangered species. In: Clauss M, Fidgett AL, Hatt JM, Huisman $\mathrm{T}$ and others (eds) Zoo animal nutrition, Vol IV. Filander Verlag, Fürth, p 169-178

Porton I (1997) International studbook for the ruffed lemur, Varecia variegata variegata and Varecia variegata rubra, 4th edn. Saint Louis Zoo, Saint Louis

Price EO (1984) Behavioral aspects of animal domestication. Q Rev Biol 59:1-32

Prout T (1969) The estimation of fitness from population data. Genetics 63:949-967

Rakotondratsima M, Kremen C (2001) Suivi écologique de deux espèces de lémuriens diurnes Varecia variegata rubra et Eulemur fulvus albifrons dans la presqu'île de Masoala (1993-1998). Lemur News 6:31-35

Rasmussen DT (1985) A comparative study of breeding seasonality and litter size in eleven taxa of captive lemurs (Lemur and Varecia). Int J Primatol 6:501-517

Ratsimbazafy JH, Ramarosandratana HV, Zaonarivelo RJ (2002) How do black-and-white ruffed lemurs still survive in a highly disturbed habitat? Lemur News 7:7-10

> Rhine RJ, Wasser SK, Norton GW (1988) Eight-year study of social and ecological correlates of mortality among immature baboons of Mikumi National Park, Tanzania. Am J Primatol 16:199-212

Richard AF, Dewar RE, Schwartz M, Ratsirarson J (2000) Mass change, environmental variability and female fertility in wild Propithecus verreauxi. J Hum Evol 39:381-391

Sauther ML (1998) The interplay of phenology and reproduction in ring-tailed lemurs: implications for ring-tailed lemur conservation. Folia Primatol 69:309-320
Savage A, Giraldo LH, Blumer ES, Soto LH, Burger W, Snowdon CT (1993) Field techniques for monitoring cotton-top tamarins (Saguinus oedipus oedipus) in Colombia. Am J Primatol 31:189-196

Schaaf CD, Stuart MD (1983) Reproduction of the mongoose lemur in captivity. Zoo Biol 2:23-38

Schmidt DA (2004) Orangutan husbandry manual: nutrition. In: Sodaro C (ed) Orangutan species survival plan husbandry manual. Chicago Zoological Society, Chicago, IL

Schwartz SM, Kemnitz JW, Howard CF Jr (1993) Obesity in free-ranging rhesus macaques. Int J Obes 17:1-9

Schwitzer C, Kaumanns W (2001a) Body weights of ruffed lemurs (Varecia variegata) in European zoos with reference to the problem of obesity. Zoo Biol 20:261-269

Schwitzer C, Kaumanns W (2001b) European regional studbook 2000 for the ruffed lemur (Varecia variegata), 5th edn. Zoologischer Garten Köln, Cologne

Schwitzer C, Kaumanns W (2004) European regional studbook 2001/2002 for the ruffed lemur (Varecia variegata), 6 th edn. Zoologischer Garten Köln, Cologne

Scobie P (1997) Single population analysis and records keeping system (SPARKS) 1.42. International Species Information System (ISIS), MN

> Shideler SE, Lindburg DG (1982) Selected aspects of Lemur variegatus biology. Zoo Biol 1:127-134

> Terranova CJ, Coffman BS (1997) Body weights of wild and captive lemurs. Zoo Biol 16:17-30

Vasey N (2003) Varecia, ruffed lemurs. In: Goodman SM, Benstead JP (eds) The natural history of Madagascar. University of Chicago Press, Chicago, IL, p 1332-1336

Vasey N (2006) The breeding system of wild red ruffed lemurs (Varecia rubra): a preliminary report. Primates 48:41-54

Vasey N, Borgerson C (2009) Social and ecological factors associated with temporary reproductive collapse in cooperatively breeding red variegated lemurs (Varecia rubra) on the Masoala Peninsula, Madagascar. Am J Phys Anthropol 138(S48):261

> Videan EN, Fritz J, Murphy J (2007) Development of guidelines for assessing obesity in captive chimpanzees (Pan troglodytes). Zoo Biol 26:93-104

Walike BC, Goodner CJ, Koerker DJ, Chideckel EW, Kalnassy LW (1977) Assessment of obesity in pigtailed monkeys. J Med Primatol 6:151-162

WAZA (World Association of Zoos and Aquariums) (2005) Building a future for wildlife - the world zoo and aquarium conservation strategy. WAZA Executive Office, Berne

> Weigler BJ, Feeser PL, Grant SM, Norris CA (1994) Epidemiologic assessment of reproductive success and infant mortality in ruffed lemurs (Varecia variegata). Zoo Biol 13:527-536

Willis E, Dartnall J, Morgan E, Kitcherside M, Gage M, Polowinsky SY, Schwitzer C (2009) Energy and nutrient intake and digestibility in captive mongoose lemurs (Eulemur mongoz). In: Clauss M, Fidgett AL, Hatt JM, Huisman $\mathrm{T}$ and others (eds) Zoo animal nutrition, Vol IV. Filander Verlag, Fürth, p 179-191

Wrangham RW (1987) Evolution of social structure. In: Smuts BB, Cheney DL, Seyfarth RM, Wrangham RW, Struhsaker TT (eds) Primate societies. University of Chicago Press, Chicago, IL, p 282-296

Wright PC (1999) Lemur traits and Madagascar ecology: coping with an island environment. Yearb Phys Anthropol 110:31-72

Submitted: January 28, 2009; Accepted: May 26, 2009

Proofs received from author(s): August 18, 2009 